\title{
Rhodococcus coprophilus sp. nov.: An Aerobic Nocardioform Actinomycete Belonging to the 'rhodochrous' Complex
}

\author{
By T. J. ROWBOTHAM AND T. CROSS \\ Postgraduate School of Studies in Biological Sciences, University of Bradford, \\ Bradford $B_{7}$ I $D P$
}

(Received 27 October 1976)

SUMMARY

The aerobic nocardioform actinomycete, found to be common in herbivore dung and aquatic habitats and previously given the trivial name Lspi, was studied along with representative strains of taxa within the 'rhodochrous' complex. Lspi strains were recovered as a homogeneous cluster which separated from the other reference strains at the $69 \%$ similarity level in a numerical taxonomic analysis. The specific name Rhodococcus coprophilus is proposed for this new species. We also consider the generic name Rhodococcus Zopf to be appropriate for most of the species currently accommodated within that rather ill-defined taxon known as the 'rhodochrous' complex and variously classified within the genera Nocardia, Mycobacterium, Jensenia, Corynebacterium or Gordona.

\section{INTRODUCTION}

Willoughby (I969) described three aerobic nocardioform actinomycetes which he isolated from Blelham Tarn, Cumbria, and its environs. One morphological type, termed 'Large spored pink irregular' (Lspi), was the most common nocardioform isolated from the aquatic habitats; its frequency in lake water and mud was confirmed by Johnston \& Cross (I976).

Strains now recognized as Lspi were included by Goodfellow (197I) in his numerical taxonomic study of nocardioform bacteria. Two were recovered in his Nocardia asteroides cluster, subgroup I B; the other three strains clustered within the 'rhodochrous' complex. However, our preliminary studies on the morphology and biochemistry of Lspi strains indicated that they were very similar to each other and belonged to the 'rhodochrous' complex. In order to further define and classify Lspi strains, we undertook a numerical taxonomic study of our isolates together with related nocardioforms, chosen from the main 'rhodochrous' clusters recovered by Goodfellow (197I), and species of the genus Gordona (Tsukamura, 197I).

\section{METHODS}

Strains. These are listed in Table I. The majority of Lspi strains were isolated from lake water and mud samples on colloidal chitin agar (Cross \& Attwell, 1974). Reference strains, from Dr M. Goodfellow, have been fully documented in previous publications (Goodfellow, 197I ; Goodfellow \& Orchard, I974; Goodfellow et al., I974; Mordarski et al., 1976). It was later realized that some strains of Gordona, received under different code numbers, were in fact the same strain. They were retained in the study because they had different histories and could indicate the reproducibility of our test methods. 
Table I. Designations and sources of strains used in the numerical taxonomic study

(a) Lspi strains

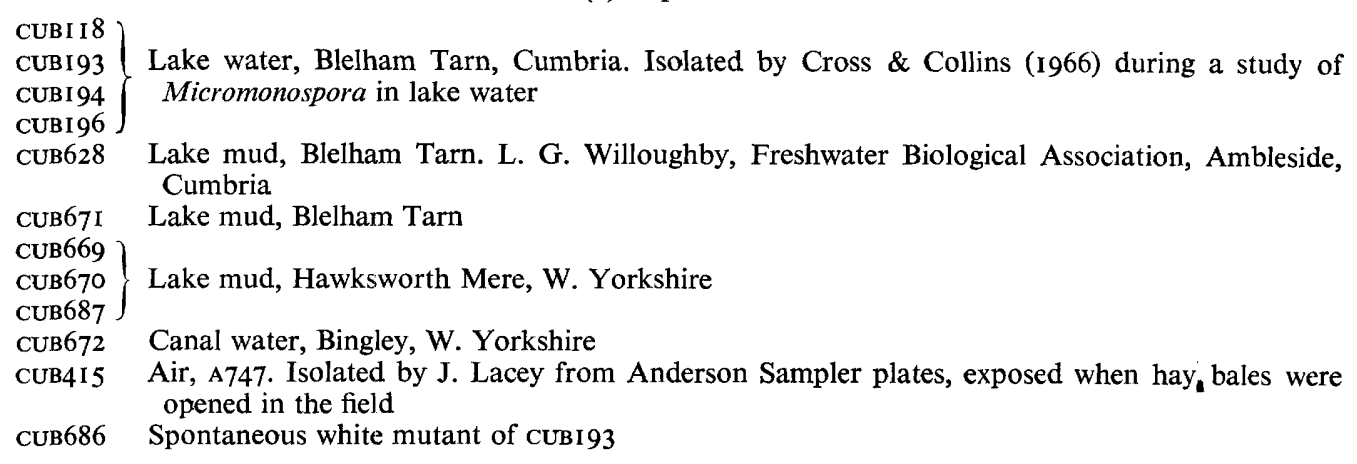

(b) Other strains

CUBI97 Nocardia sp. Lake water, Blelham Tarn (Cross \& Collins, 1966)

CUB710 Corynebacterium rubrum NCIB9433

CUB673 Nocardia corallina Batt (Robertson \& Batt, 1973)

CUB685 Nocardia-like soil bacterium, Lingens AI (Bachofer, Oltmanns \& Lingens, 1973)

CUB7I I N. corallina A8I (Crawford et al., I973)

CUB642 Nocardia erythropolis NII, NCIB9I58

Cư643 Nocardia pellegrino N324, ATCCI 5998

CUB644 Nocardia opaca NI 24, CBS330.6I

CUB645 Rhodococcus rhodochrous N54, ATCCI 3808

CUB646 Mycobacterium rhodochrous (N. erythropolis) NI08, ATCC4277

CUB647 Jensenia canicruria $\mathrm{N53}$, NCIB8I47

CUB674 Nocardia calcarea $\mathrm{N4I}$, NCIB8863

CuB675 M. rhodochrous N66, NCTC8I39

CUB7I2 N. pellegrino $\mathrm{N} 325$

CUB7I3 Nocardia salmonicolor $\mathrm{N5}$, NCIB970

CUB677 Gordona rubra N655, NCTC10668

cuB679 G. rubra N657 (Mordarska T3), NCTCI0668

CUB678 Gordona terrae N656, NCTC10669

cuB680 G. terrae N659 (Mordarska T5), NCTCI0669

CUB683 G. terrae N662 (Mordarska T6)

CUB676 Gordona bronchialis N654, NCTCI0667

CUB68I G. bronchialis N660 (Mordarska Tr), NCTC10667

CUB682 G. bronchialis N661 (Mordarska T2)

CuB684 Gordona aurantiaca N663, NCTCI074I

CUB, Actinomycete Culture Collection, University of Bradford; N, M. Goodfellow, University of Newcastle upon Tyne; NCIB, National Collection of Industrial Bacteria; ATCC, American Type Culture Collection; NCTC, National Collection of Type Cultures; CBs, Centraalbureau voor Schimmelcultures, Baarn, The Netherlands.

All strains were freeze-dried and working cultures were maintained on Bennett's agar. Growth media and preparation of standard suspensions. Strains were routinely subcultured on Bennett's agar containing $\left(\mathrm{g}^{-1}\right.$ ): yeast extract (Difco), I ; beef extract (Lab Lemco powder, Oxoid), I; Bacto Casitone (Difco), 2; glucose, I0; and agar, I8; final pH 7.3. Bacterial suspensions were grown in shaken flasks of Bennett's broth or of PYG broth, which contained ( $\left.\mathrm{g}^{-1}\right)$ : Bacto peptone (Difco), 5; yeast extract (Difco), 5; glucose, Io; Casamino acids (Difco), I; and $\mathrm{NaCl}, 5$; final $\mathrm{pH} 7 \cdot 2$. All cultures were incubated at $30^{\circ} \mathrm{C}$. Bacteria for chemical analyses were treated with formaldehyde before washing and freeze-drying.

Standard bacterial suspensions for all growth and utilization tests were stored in semisolid agar at $4{ }^{\circ} \mathrm{C}$ (Kützner, 1972). Strains were grown in Bennett's broth in shake flasks for 
5 days, washed twice with distilled water, and resuspended to give an $E_{660}$ value of 0.4 . Samples $(5 \mathrm{ml})$ of this suspension were added to screw-capped bottles each containing $5 \mathrm{ml}$ warm $\left(40^{\circ} \mathrm{C}\right)$ water agar [Oxoid agar no. $3\left(2 \cdot 5 \mathrm{~g} \mathrm{l}^{-1}\right)$ containing thiamin. $\mathrm{HCl}\left(8 \mathrm{mg} \mathrm{l}^{-1}\right)$ ]. Fresh inocula of most strains were prepared monthly; however, the viability of three Lspi strains (CUB669, CUBI93 and CUB686) and one strain of Gordona bronchialis (CUB682) declined rapidly and, for these, fresh inocula were prepared as required.

The basal medium for utilization tests was that of Stevenson (1967), but with a higher concentration of $\mathrm{K}_{2} \mathrm{HPO}_{4}\left(3 \mathrm{~g} \mathrm{l}^{-1}\right)$ to raise the $\mathrm{pH}$. All test media had a final $\mathrm{pH}$ of $7 \cdot 0$. Most nocardioform bacteria tested required thiamin for growth and accordingly membranefiltered thiamin. $\mathrm{HCl}$ solution was added at $4 \mathrm{mg} \mathrm{l}^{-1}$ to all media deficient in this vitamin.

Morphological characters. Plates of Bennett's agar were inoculated for single colonies and examined microscopically after $24 \mathrm{~h}$ with a $\times 40$ (N.A. 0.57 ) long working distance objective (Vickers Instruments, York). The presence of aerial hyphae was noted and the microcolonies were divided into two categories: either predominantly composed of rods and branching fragments, or remaining essentially mycelial. After 3 days, smears were stained by Hucker's modification of the Gram stain (Conn, Bartholomew \& Jennison, I957). The diameter of isolated colonies was measured after 7 days and the presence of substrate mycelium, and rhizoid or asteroid colonies with a central papilla was noted. Tubes of Bennett's broth, incubated for 3 days, were examined for the presence of a pellicle. Strains with growth extending across the broth surface and up the sides of the tube were scored as positive, no surface growth or few isolated colonies as negative.

Chemotaxonomic characters. Mycolic acids were detected using a thin-layer chromatographic method which distinguishes between two of the lipid LCN-A (lipid characteristic of Nocardia) analogues, LCN-A type a (asteroides) and LCN-A type c (calcarea) (Mordarska, Mordarski \& Goodfellow, 1972; Minnikin \& Goodfellow, 1976). The isomers of diaminopimelic acid in whole-cell hydrolysates were detected by paper chromatography (Becker, Lechevalier \& Lechevalier, 1965) using the solvent system methanol/water/pyridine/ $98 \%(\mathrm{v} / \mathrm{v})$ formic acid (80: 19:10: I, by vol.) (Perkins, I965). Sugars were detected by paper chromatography using the solvent system butan-I-ol/pyridine/water/toluene $(5: 3: 3: 4$, by vol.) (Lechevalier, 1968). Freeze-dried preparations of Nocardia asteroides NCTC8595, N. brasiliensis ATCC19296, Rhodococcus rhodochrous cuB645 and Streptomyces griseus CUB575 were used as reference standards.

Utilization of organic compounds as sole sources of carbon and energy. Test compounds (listed in Tables 2 and 3 ) in the solidified basal medium in divided polystyrene Replidishes (Sterilin, Richmond, Surrey) were inoculated with standard suspensions by means of a multipoint inoculator (Denley Instruments, Bolney, Sussex). Plates containing basal medium only and basal medium plus $0 . \mathrm{I} \%(\mathrm{w} / \mathrm{v})$ glucose were also inoculated as controls. Results were recorded after I, 2 and 3 weeks incubation. Tests were performed once but were repeated if the results were inconclusive. A positive result was registered if growth on the test medium was greater than on the control medium without a carbon source, and negative where growth was less than that on the basal medium plus glucose.

Thiamin requirement and growth on wax. Bacteria grown in Bennett's broth were washed and resuspended for $40 \mathrm{~h}$ in a glucose/nitrate mineral salts starvation medium lacking thiamin. The resultant suspension was washed repeatedly, resuspended in phosphate buffer $\mathrm{pH} 7.0$ to give $E_{660}=0.2$, and $0.05 \mathrm{ml}$ samples were then added to $10 \mathrm{ml} \mathrm{McClung's}$ (1960) carbon-free mineral salts medium in Universal bottles containing wax-coated glass slides $(\mathrm{I} 2 \times 75 \mathrm{~mm})$. Duplicate bottles containing added thiamin $\left(4 \mathrm{mg} \mathrm{l}^{-1}\right)$ were also inoculated. After 3 weeks incubation in the dark, slides were compared. Growth on the 
paraffin wax in the thiamin supplemented medium, which usually occurred at the air/liquid/ wax interface, and little or no growth on the control slide was taken to indicate a requirement for thiamin. Slide cultures were incubated for a further week, one set in the dark and another in continuous bright light in order to detect any increase in pigmentation indicating partial photochromogenicity.

This method was also used to compare the ability of strains to grow on paraffin wax, cetyl alcohol and stearic acid as sole carbon sources.

Resistance to inhibitory agents. The effects of $\mathrm{NaCl}$, sodium azide and $p$-nitrophenol in Bennett's agar were recorded after 3 weeks incubation.

Hydrolysis of insoluble organic compounds. Agar media, containing a suspension of the test compound, were inoculated with $0.05 \mathrm{ml}$ standard suspension and examined for clear zones around the inoculum after incubation. The hydrolysis of adenine, elastin, guanine, xanthine, tyrosine or casein was detected in the basal media and by methods used by Gordon (1968). Tyrosinase activity was determined in plates incubated at $20^{\circ} \mathrm{C}$ and $30^{\circ} \mathrm{C}$ because some strains showed evidence of enzyme activity only at the lower incubation temperature. Chitin hydrolysis was tested in a colloidal chitin agar (Cross \& Attwell, 1974), and cellulose hydrolysis in the basal medium of Eggins \& Pugh (I 962) containing $\mathrm{I} \cdot 0 \%$ (w/v) cellulose powder (MN-300; Macherey, Nagel \& Co., Germany).

Antibiotic sensitivity tests. Filter paper discs containing antibiotics (Goodfellow \& Orchard, 1974) were placed on Diagnostic Sensitivity Test agar (Oxoid), with added thiamin (4 $\mathrm{mg}^{-1}$ ), spread with $0^{\circ} \mathrm{I} \mathrm{ml}$ standard suspension of the test organism per $90 \mathrm{~mm}$ diam. plate. Plates were incubated for 5 days. Strains showing inhibition zones $>0.5 \mathrm{~mm}$ were recorded as sensitive.

Additional tests. Hydrolysis of Tween 80 was detected by the method of Sierra (1957) and of DNA by the method of Jeffries, Holtman \& Guse (1957). Urease was detected in the medium of Gordon \& Mihm (1959) solidified with agar. Bacterial growth on Bennett's agar was used for catalase and oxidase tests (Steel, 196I). Ability to grow on $\mathrm{M}_{3}$ isolation medium containing nitrate, propionate and thiamin (Rowbotham \& Cross, 1977) was also recorded.

Collection and coding of data. For each strain, I Io unit characters were studied. The results of 32 tests of no discriminatory value (Table 2) were not included for computation. All tests were designed to have only two states, positive or negative; a result that was still inconclusive after retesting was coded as negative.

Data analysis and presentation. The simple matching coefficient $\left(S_{\mathrm{SM}}\right)$ (Sokal \& Michener, 1958) was used and the unsorted similarity matrix produced was converted to a sorted similarity matrix and phenogram (Fig. 6) by a highest single linkage procedure (Lessel \& Holt, 1970).

\section{RESULTS AND DISCUSSION}

\section{Morphology and growth requirements}

Lspi strains did not produce a pellicle on Bennett's broth after 3 days incubation, although isolated floating colonies sometimes occurred. This is in contrast to most of the rhodochrous strains studied (Table 3) which formed a definite pellicle. On Bennett's agar plates inoculated for single colonies, three colony forms of Lspi were often observed (Fig. I): effuse rhizoidal colonies with a central orange papilla (A); colonies with a large central papilla and a narrow mycelial fringe (B); and colonies with a much larger, irregular, wrinkled papilla and no mycelial fringe (C). Well-isolated colonies on rich media, such as Bennett's agar, tended to be of form $\mathrm{C}$; colonies on poor media or where nutrients were limited because of overcrowding were of form $\mathrm{A}$. Intermediate forms between $\mathrm{A}$ and $\mathrm{C}$ occurred and reflected 
Table 2. Tests of no discriminatory value (total 32) when comparing Lspi with 'rhodochrous' strains

(a) Tests for which all 36 strains were positive

I Gram stain (positive)

2 Catalase

3 Growth on $\mathrm{M}_{3}$ isolation medium

Sole carbon source $(\%, w / v)$ :

$\begin{array}{rlr}4 & \text { Sodium acetate } & (\mathrm{O} \cdot \mathrm{I}) \\ 5 & \text { Sodium propionate } & (\mathrm{O} \cdot \mathrm{I}) \\ 6 & \text { Sodium isobutyrate } & (\cdot \mathrm{I}) \\ 7 & \text { Sodium valerate } & (\mathrm{O} \cdot \mathrm{I}) \\ 8 & \text { D-Glucose } & (\mathrm{I} \cdot 0) \\ 9 & \text { D-Fructose } & (\mathrm{I} \cdot 0) \\ 10 & \text { D-Mannose } & (\mathrm{I} \cdot 0)\end{array}$

(b) Tests for which all 36 strains were negative

I Oxidase

2 Growth on Bennett's agar $+p$-nitrophenol $\quad(0.05 \%$, w/v)

Hydrolysis of:

3 Casein

4 Cellulose

5 Chitin

6 Elastin

7 Guanine

8 Xanthine

Sole carbon source $(\%, w / v)$ :

9 Sodium glycollate

ro Sodium mandelate

$(0.05 \%, w / v)$

I Sodium tartrate

$(\mathrm{I} \cdot 0 \%, \mathrm{w} / \mathrm{v})$

$(0.3 \%, w / v)$

$(0 \cdot 2 \%, w / v)$

$(0.2 \%, w / v)$

$(0 \cdot I)$

$(0 \cdot 1)$

$(0 \cdot 1)$

2 Sodium 2,2-dichloropropionate ('Dalapon' herbicide)

$o$-Hydroxybenzaldehyde

Biphenyl

Nicotinamide

Pyrazinamide

Ethane-I,2-diol

D-Cellobiose

Dulcitol

Inulin

Cholesteryl acetate

$\beta$-Carotene

$(0 \cdot 05)$

nutrient availability. To facilitate recognition and enumeration of Lspi, the concentration of the sole carbon source in the $\mathrm{M}_{3}$ isolation medium (Rowbotham \& Cross, 1977) was adjusted so that the characteristic form $\mathrm{A}$ colonies were produced. Unlike most other rhodochrous strains (Table 3), growth of Lspi strains extended into the agar (Fig. I).

Colony pigmentation was enhanced by exposure to light indicating partial photochromogenicity. Lspi strains required thiamin to utilize paraffin wax as a sole carbon source. Growth and pigmentation were reduced on media deficient in thiamin.

Impression smears, prepared from the central papilla, contained branched chains and complex aggregates of Gram-positive, non acid-fast coccoid elements ( $\cdot \circ$ to I $5 \mu \mathrm{m} \mathrm{diam}$.) (Fig. 2). In old cow-dung and other materials containing high numbers of Lspi, similar coccoids were seen. Consequently, a colony-forming unit of Lspi from dung or other substrates may be one or a short chain of coccoids still joined together. The diameter of the vegetative mycelium rarely exceeded $\mathrm{I} \cdot 0 \mu \mathrm{m}$ although short lengths of swollen, irregular hyphae sometimes occurred. Large spherical bodies or cystites were occasionally seen in the 
Table 3. Frequency of positive characters (numbers of strains positive) in clusters defined at the $80 \%$ similarity level

Cluster

No. of strains tested

Characters

${ }^{*}$ I Bennett's broth $\left(3\right.$ days, $\left.30^{\circ} \mathrm{C}\right)$, presence of pellicle

Bennett's agar $\left(30^{\circ} \mathrm{C}\right)$ :

*2 Microcolonies, mycelial ( $24 \mathrm{~h}$ )

*3 Microcolonies, rods and branching fragments $(24 \mathrm{~h})$

*4 Rudimentary aerial mycelium ( 24 h)

*5 Sub-surface mycelium (7 days)

*6 Asteroid colonies with central papilla ( 7 days)

*7 Separate colonies $<2.5 \mathrm{~mm}$ diam. (7 days)

Growth on Bennett's agar in the presence of:

8 Sodium chloride $(5 \%, w / v)$

*9 Sodium chloride $(7 \%, w / v)$

I0 Sodium azide $(0.01 \%, \mathrm{w} / \mathrm{v})$

Hydrolysis of:

* I I L-Tyrosine $(0.2 \%, w / v)$

* I2 Adenine $(0.5 \%, \mathrm{w} / \mathrm{v})$

I3 [Inhibition by adenine]

14 DNA

I5 Urea

* 6 Tween 80

Sole carbon source $(\%, w / v)$ :

17 Stearic acid

I 8 Cetyl alcohol

19 Paraffin wax (m.p. $60^{\circ} \mathrm{C}$ )

*20 Thiamin required for Paraffin wax to be used as sole carbon source

*2I [Partially photochromogenic]

22 Sodium butyrate

*23 tri-Sodium citrate

24 Sodium lactate

*25 Sodium L-malate

*26 Sodium succinate

27 Sodium benzoate

* 28 Sodium $m$-hydroxybenzoate

*29 Sodium $p$-hydroxybenzoate

*30 Acetamide

3I Benzamide

32 L-Alanine

33 D-Alanine

*34 DL-Norleucine

35 L-Proline

36 L-Serine

37 L-Tyrosine

38 Propane-1,2-diol

*39 Butane-I,3-diol

40 Butane-I,4-diol

*4I Glycerol
$(0 \cdot 1)$

$(0 \cdot 1)$

$(0 \cdot 1)$

(O.I)

$(0 \cdot 1)$

$(0 \cdot I)$

$(0 \cdot 1)$

$(0 \cdot 1)$

$(0 \cdot 1)$

$(0 \cdot I)$

(O.I)

$(0 \cdot 1)$

$(0 \cdot \mathrm{I})$

$(0 \cdot I)$

$(0 \cdot 1)$

(I.0)

$(\mathrm{I} \cdot \mathrm{O})$

$(\mathrm{I} \cdot \mathrm{O})$

(I O )

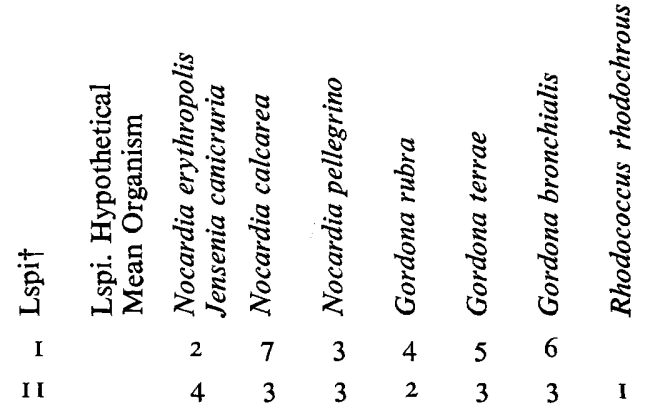

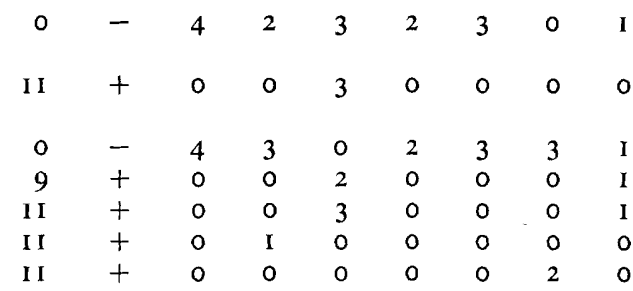

$\begin{array}{lllllllll}7 & + & 4 & 3 & 3 & 2 & 3 & 3 & \text { I } \\ 0 & - & 0 & 0 & 2 & 2 & 3 & 3 & \text { I }\end{array}$

I $+\begin{array}{lllllll}4 & 4 & 3 & 2 & 3 & 2 & \text { I }\end{array}$ 
Table 3. (contd.)
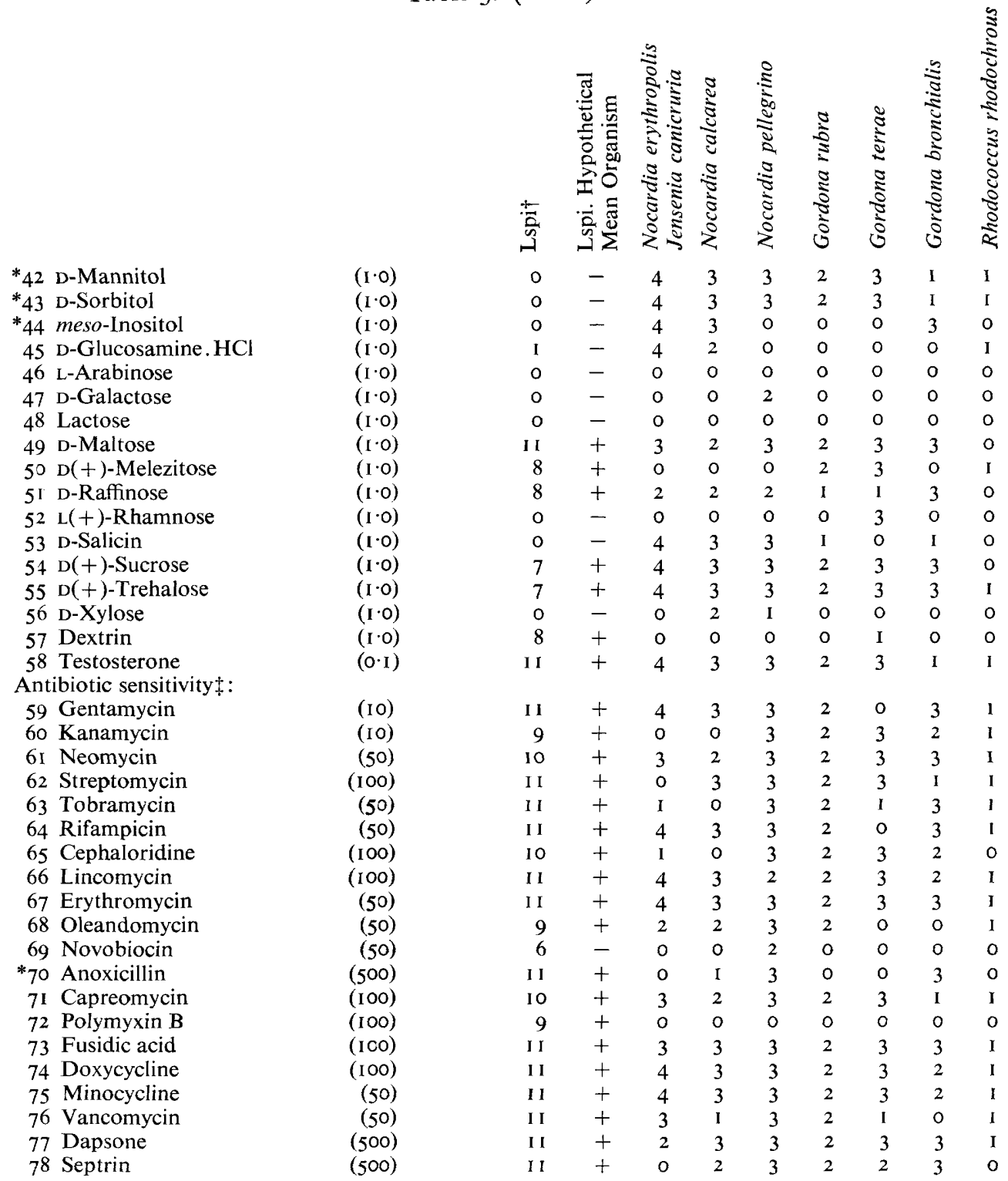

\begin{tabular}{|c|c|c|c|c|c|c|c|}
\hline 0 & - & 4 & 3 & 3 & 2 & 3 & I \\
\hline 0 & - & 4 & 3 & 3 & 2 & 3 & I \\
\hline 0 & - & 4 & 3 & 0 & 0 & 0 & 3 \\
\hline I & - & 4 & 2 & 0 & 0 & 0 & 0 \\
\hline 0 & - & 0 & 0 & 0 & 0 & 0 & 0 \\
\hline 0 & - & 0 & 0 & 2 & 0 & 0 & 0 \\
\hline o & - & 0 & 0 & 0 & 0 & 0 & 0 \\
\hline I I & + & 3 & 2 & 3 & 2 & 3 & 3 \\
\hline 8 & + & 0 & 0 & 0 & 2 & 3 & 0 \\
\hline 8 & + & 2 & 2 & 2 & I & I & 3 \\
\hline 0 & - & 0 & 0 & 0 & 0 & 3 & 0 \\
\hline 0 & - & 4 & 3 & 3 & 1 & 0 & I \\
\hline 7 & + & 4 & 3 & 3 & 2 & 3 & 3 \\
\hline 7 & + & 4 & 3 & 3 & 2 & 3 & 3 \\
\hline 0 & - & 0 & 2 & I & 0 & 0 & 0 \\
\hline 8 & + & 0 & 0 & 0 & 0 & I & 0 \\
\hline I I & + & 4 & 3 & 3 & 2 & 3 & I \\
\hline I I & + & 4 & 3 & 3 & 2 & 0 & 3 \\
\hline 9 & + & 0 & 0 & 3 & 2 & 3 & 2 \\
\hline 10 & + & 3 & 2 & 3 & 2 & 3 & 3 \\
\hline I I & + & 0 & 3 & 3 & 2 & 3 & I \\
\hline 11 & + & I & 0 & 3 & 2 & I & 3 \\
\hline I I & + & 4 & 3 & 3 & 2 & 0 & 3 \\
\hline 10 & + & I & 0 & 3 & 2 & 3 & 2 \\
\hline I I & + & 4 & 3 & 2 & 2 & 3 & 2 \\
\hline I I & + & 4 & 3 & 3 & 2 & 3 & 3 \\
\hline 9 & + & 2 & 2 & 3 & 2 & 0 & 0 \\
\hline 6 & - & 0 & 0 & 2 & 0 & 0 & 0 \\
\hline I I & + & 0 & I & 3 & 0 & 0 & 3 \\
\hline 10 & + & 3 & 2 & 3 & 2 & 3 & I \\
\hline 9 & + & 0 & 0 & 0 & 0 & 0 & 0 \\
\hline I I & + & 3 & 3 & 3 & 2 & 3 & 3 \\
\hline 11 & + & 4 & 3 & 3 & 2 & 3 & 2 \\
\hline I 1 & + & 4 & 3 & 3 & 2 & 3 & 2 \\
\hline I I & + & 3 & I & 3 & 2 & I & 0 \\
\hline I I & + & 2 & 3 & 3 & 2 & 3 & 3 \\
\hline I I & + & 0 & 2 & 3 & 2 & 2 & 3 \\
\hline
\end{tabular}

Additional sole carbon source tests§ $(0.1 \%, w / v)$ :

Sodium adipate

* Sodium gluconate

* Sodium $\gamma$-aminobutyrate

* Sodium phenylacetate

* L-Phenylalanine

* L-Asparagine Glycine

* Selected distinguishing characters for Lspi.

+ cuB686, a white mutant of cuBr93, was not included.

+ Numbers in parentheses indicate the concentration of antibiotic $\left(\mu \mathrm{g} \mathrm{ml}^{-1}\right)$ in which the disc was dipped.

$\S$ Also found useful for separating species. 
Colony form

Surface view
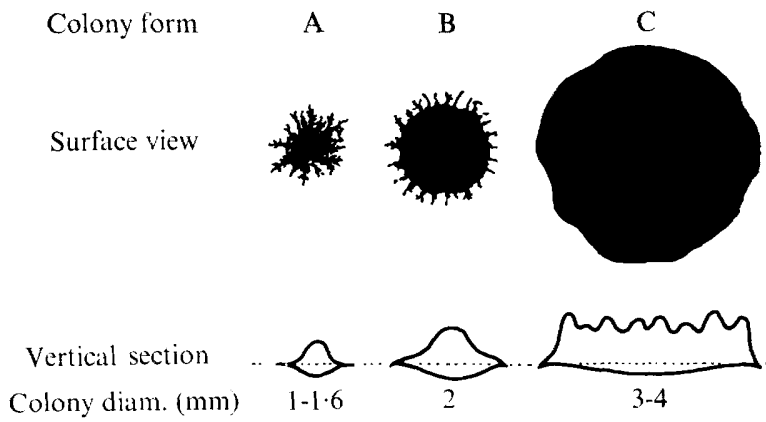

agar surface

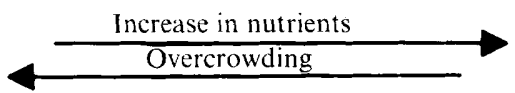

Fig. I. Colony forms of an Lspi strain observed on Bennett's agar incubated for 2 weeks at $30{ }^{\circ} \mathrm{C}$ : A, effuse rhizoidal colonies with a central orange papilla; $\mathrm{B}$, colonies with a large central papilla and a narrow mycelial fringe; $\mathrm{C}$, colonies with a larger, irregular, wrinkled papilla and no mycelial fringe.

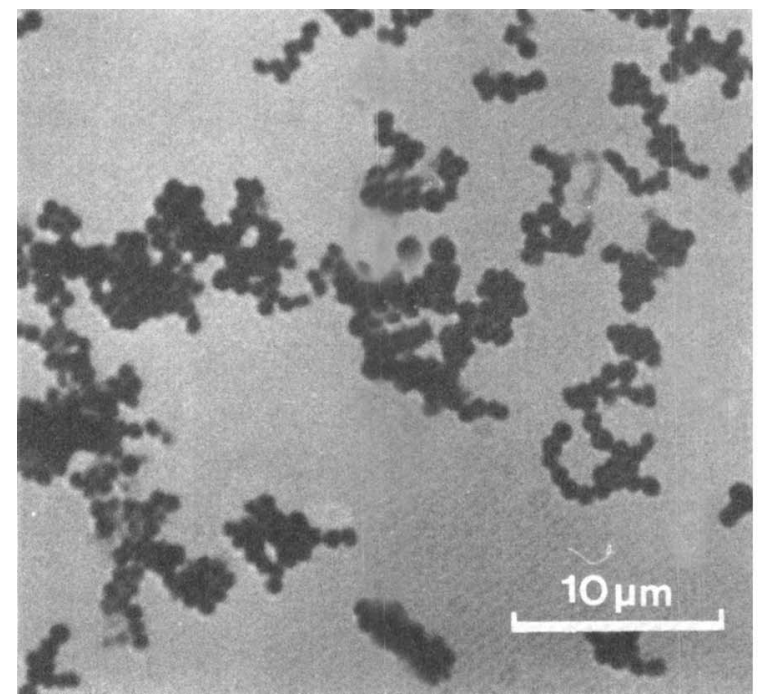

Fig. 2.

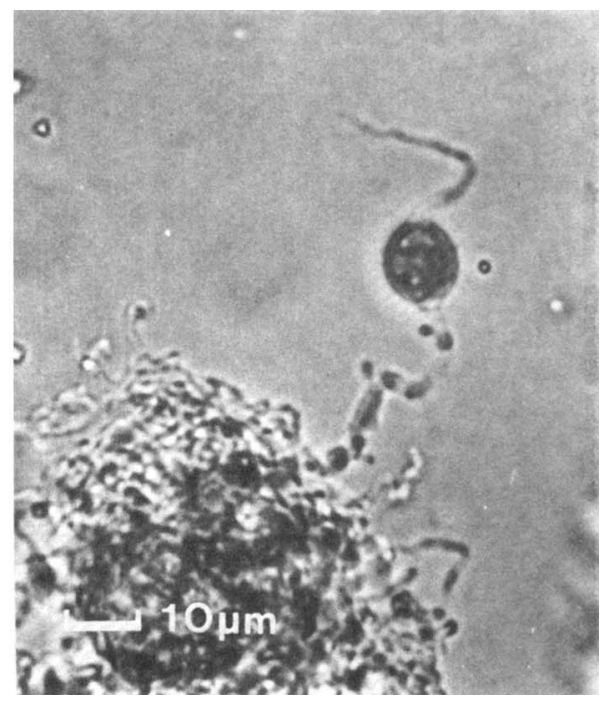

Fig. 3.

Fig. 2. Gram-stained impression smear from the central papilla of an Lspi colony: strain cuB687 grown on Bennett's agar at $30^{\circ} \mathrm{C}$ for I week.

Fig. 3. A cystite at the edge of an Lspi colony: strain cuB670 grown on Bennett's agar at $25^{\circ} \mathrm{C}$ for 2 weeks.

mycelial fringe around colonies; they were usually subterminal (Fig. 3) and occurred more frequently in certain strains (e.g. cuB670).

Colonial development. A uniform and just visibly turbid suspension of CUB687 in Bennett's broth was prepared from the central papilla of a I-week-old colony on Bennett's agar. One drop of this suspension, spread on a $90 \mathrm{~mm}$ plate of the same agar, was incubated on a microscope stage at $30{ }^{\circ} \mathrm{C}$. The growth of one coccoid was photographed at o h and at hourly intervals from $\mathrm{I} 2 \mathrm{~h}$ to $24 \mathrm{~h}$ (Fig. 4). By $\mathrm{I} 2 \mathrm{~h}$ most of the coccoids had produced several germ tubes which developed into a branched primary mycelium. Growth into the agar occurred after $\mathrm{I} 5 \mathrm{~h}$ and production of the central papilla commenced after $\mathrm{I} 8 \mathrm{~h}$. One aerial 


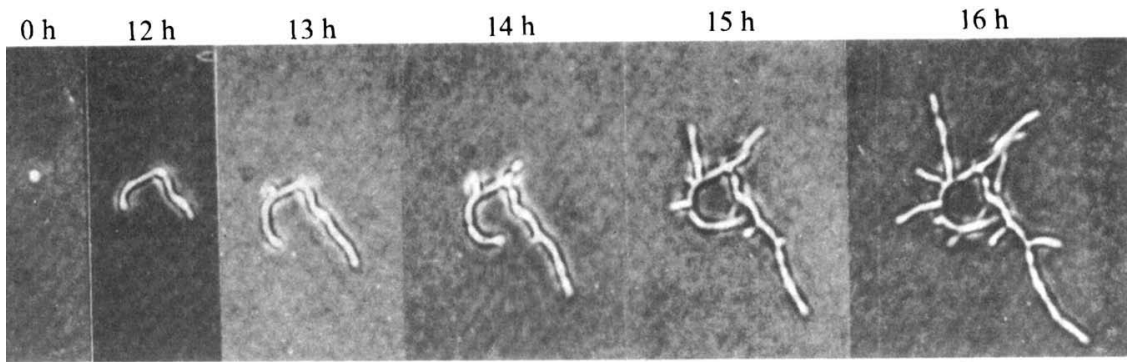

$17 \mathrm{~h}$

$18 \mathrm{~h}$

$19 \mathrm{~h}$

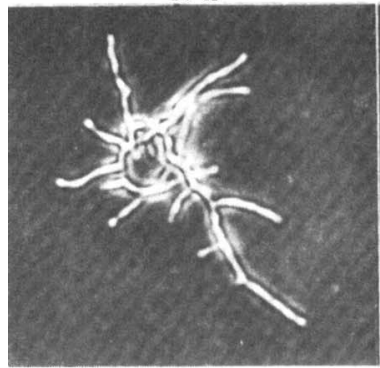

$20 \mathrm{~h}$

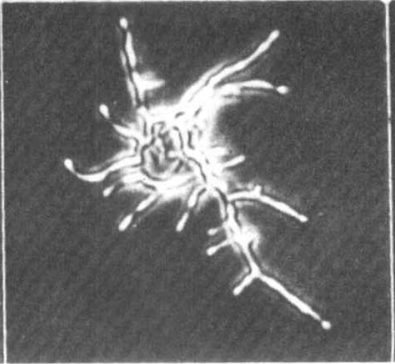

$21 \mathrm{~h}$
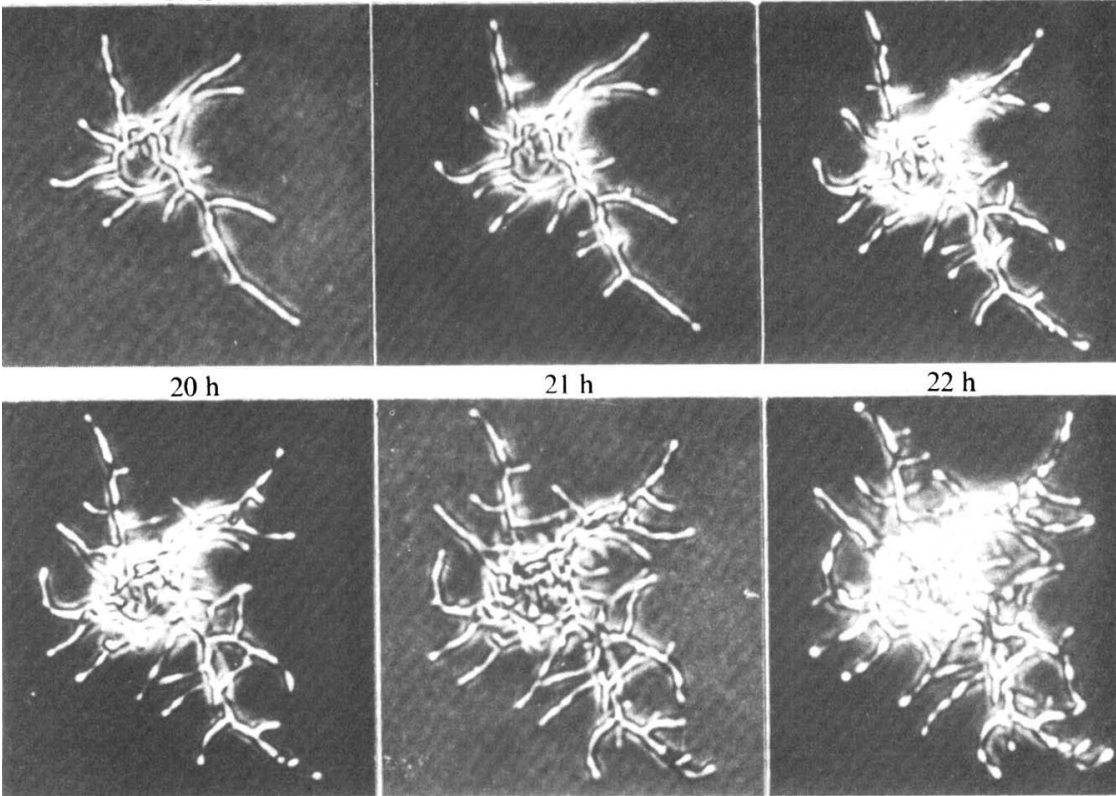

$22 \mathrm{~h}$

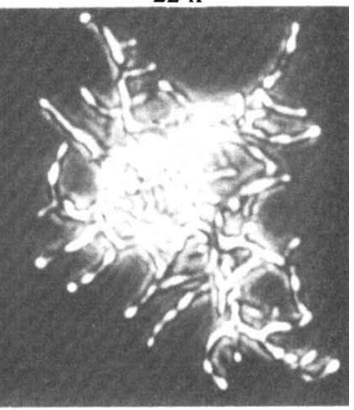

$23 \mathrm{~h}$

$24 \mathrm{~h}$
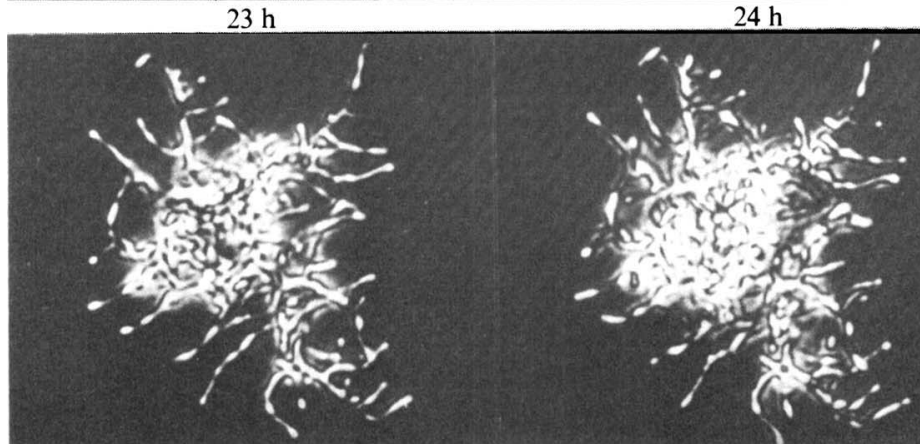

Fig. 4. Mycelial growth of an Lspi strain (CuB687) on Bennett's agar during $24 \mathrm{~h}$ incubation at $30^{\circ} \mathrm{C}$.

hypha was visible after $2 \mathrm{I} \mathrm{h}$ and three after $24 \mathrm{~h}$. Cross-walls were seen after $\mathrm{I} 2$ to $\mathrm{I} 4 \mathrm{~h}$ incubation (Fig. 5). Hyphae in the region of the central papilla became subdivided at regular intervals, and the units enlarged to form the spherical coccoids. These development stages indicate that Lspi strains could be included in McClung's (I954) Group II morphological subdivision of the nocardiae. 


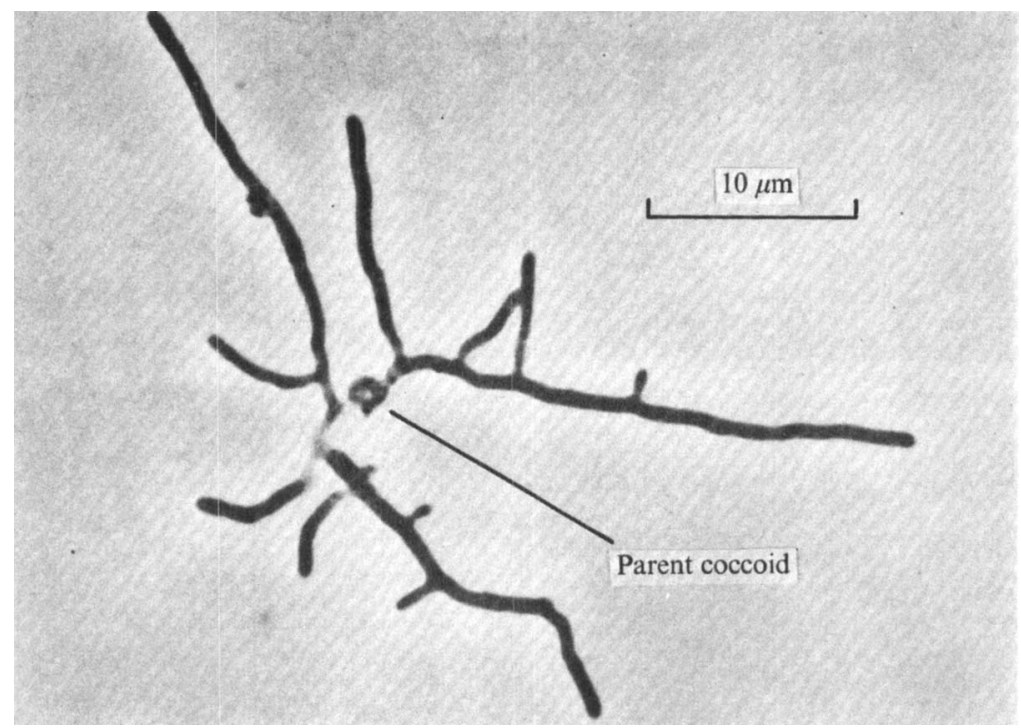

Fig. 5. Microcolony of an Lspi strain (CUB687) on Bennett's agar after $\mathrm{I} 4 \mathrm{~h}$ incubation at $30^{\circ} \mathrm{C}$ showing the parent coccoid and mycelium with few cross-walls.

The hyphae of CUBI 18 divided into irregular fragments instead of coccoids. When transferred to fresh media these fragments or portions of them enlarged to form club- or lemonshaped bodies which later germinated. Growth of CUB687 on the EGYA medium of Cure \& Keddie (1973) was slower with a more extended mycelial phase than on Bennett's agar; no cross-walls were seen at $24 \mathrm{~h}$.

The microcolonies of Lspi strains were similar to those of Nocardia pellegrino strains but quite distinct from those of other rhodochrous strains examined (Table 3).

\section{Chemotaxonomy}

Whole-organism material from the 12 Lspi strains contained meso-diaminopimelic acid and large amounts of arabinose and galactose, consistent with a type IV wall composition (Becker et al., 1965). This wall composition is found in the genera Corynebacterium, Mycobacterium, Nocardia and members of the 'rhodochrous' complex; however, the mycolic acids of these taxa vary in chain length and structure. Lspi strains contained lipid LCN-A with a lower $R_{F}$ than that of Nocardia asteroides and Nocardia brasiliensis but with a mobility similar to that of LCN-A from Rhodococcus rhodochrous. The DNA base composition of Lspi strains was 60 to $64 \mathrm{~mol} \%$ GC (Mordarski et al., 1977).

\section{Numerical taxonomy}

At the $90 \%$ similarity level $(\% \mathrm{~S})$ there were five main clusters: Lspi, Nocardia erythropolis/Jensenia canicruria, N. pellegrino, Gordona rubra and G. terrae (Fig. 6). At $83 \% \mathrm{~S}$ the three G. bronchialis strains united with themselves (cluster 6) and with clusters 4 and 5. At 87 to $88 \%$ S, three strains including $N$. calcarea, called cluster 7 , joined cluster 2 containing $N$. erythropolis and J. canicruria (Fig. 6). Table 3 shows the frequency of positive characters in clusters defined at the $80 \%$ similarity level.

Cluster I: Lspi. The Lspi strains formed a homogeneous cluster which was clearly 


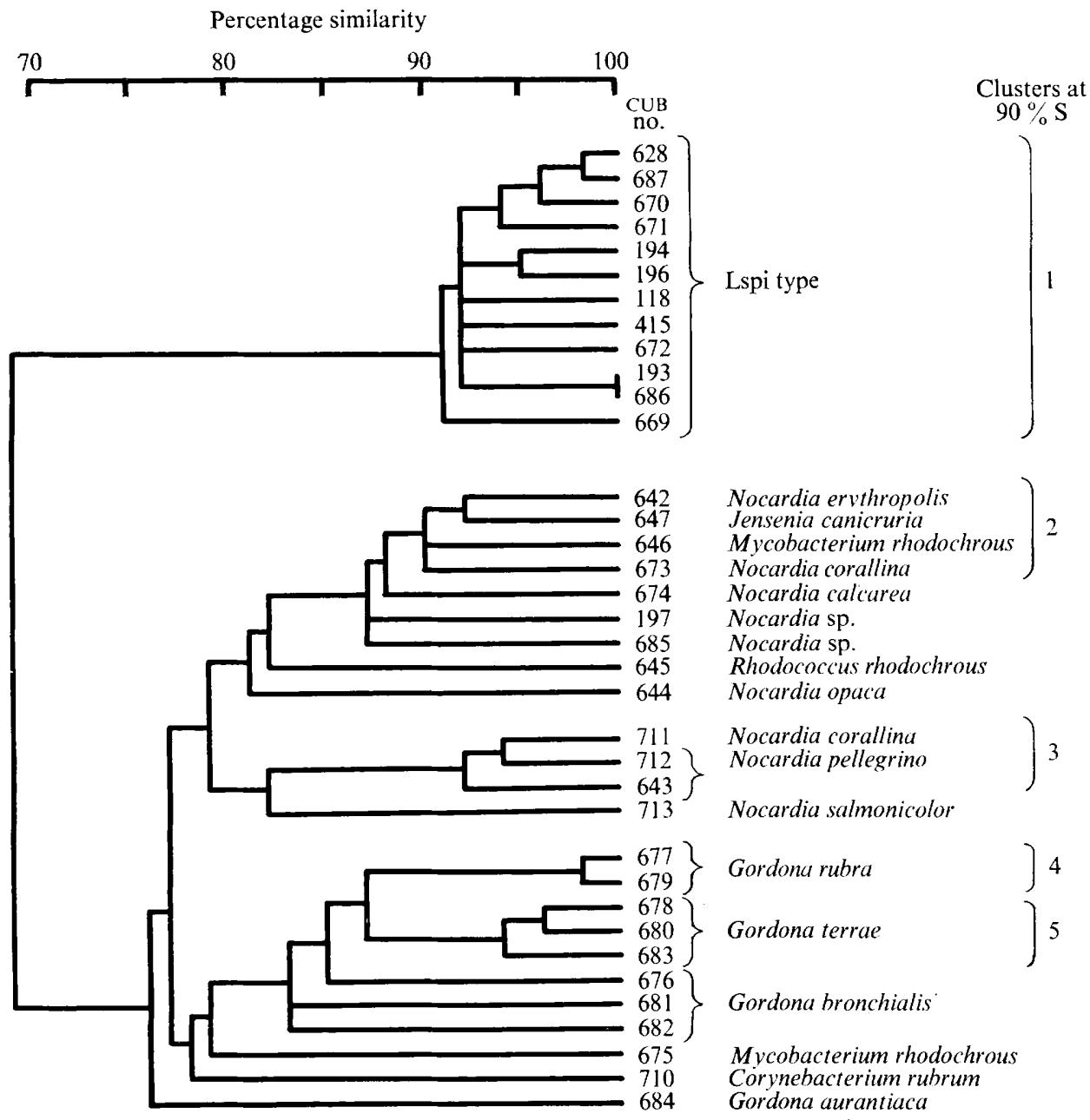

Fig. 6. Cluster analysis by the highest single linkage method.

separated from the other nocardioforms tested, and did not include any of the reference strains studied (Fig. 6).

Goodfellow (197I) included five Lspi strains in his numerical taxonomic studies on nocardioform bacteria. These early strains had been inadequately characterized; the colony morphology and presence of a visible mycelium had suggested that some strains might belong to the then ill-defined species Nocardia asteroides. Consequently, he received CUBII 8 (N249) as 'N. asteroides subgroup', CUB4I5 (N265) as a 'Nocardia sp. asteroides type', and CUB 193, 194 and 196 as 'Nocardia sp.'. Because of the large number of strains, Goodfellow carried out his analysis in two parts, one containing the potentially pathogenic nocardiae, the other the so-called soft-growing nocardioform organisms. Thus CUBII 8 and CUB4I 5 were included in the first analysis, where they grouped with $N$. asteroides strains in cluster subgroup IB. The other Lspi strains included in the second analysis were allocated to the 'rhodochrous' cluster, subgroup ${ }_{14} \mathrm{G}$, a heterogeneous subgroup containing mainly unnamed strains. 
In a further numerical study (Goodfellow, Fleming \& Sackin, 1972), the Lspi strains CUBI93 and CUBI94 were again recovered outside the main clusters of rhodochrous strains, but did not fall within the mycobacteria or coryneforms. Strains CUBI93 and CUBI94 are very similar to the other Lspi strains and their position at the edge of the 'rhodochrous' complex was confirmed by our studies.

Lspi strains differ from Nocardia asteroides in their morphology. None of those examined in this study, or subsequently isolated from a variety of habitats (Rowbotham \& Cross, 1977), produced a visible aerial mycelium on agar media. The very short and infrequent aerial hyphae that were observed could only be seen with the aid of a microscope. The orange-red colonies did not excrete melanin or other water-soluble pigments and elements of the fragmenting mycelium enlarged to give the characteristic cocci observed by Willoughby (I969). Other differences noted included the lower mobility of the lipid LCN-A on thinlayer chromatograms and the inability of Lspi strains to utilize succinate, glycerol or mannitol as the sole carbon source. Lspi strains were also more sensitive to the antibiotics benzylpenicillin and cephaloridine.

Lspi strains require thiamin for growth and the lack of this vitamin in some of the test media used by Goodfellow (I97I) possibly influenced the disparate clustering of Lspi by introducing a high number of negative results. When Goodfellow excluded the negative matches, a greater weighting was placed on the fewer positive matches, and the morphological characters used contributed to the clustering of the two Lspi strains with Nocardia asteroides.

Clusters 4,5 and 6 were recognized by Tsukamura (1973, 1974) as different species of the genus Gordona. It is therefore reasonable to equate cluster I to a species. Lspi strains can be assigned to the 'rhodochrous' complex on morphological, chemotaxonomic and numerical taxonomic grounds. None of the other nocardioforms clusters with Lspi, nor has a literature search or communications with other workers revealed any named strains identifiable as Lspi. Lspi strains thus appear to be a new species belonging to the 'rhodochrous' complex.

A good type strain should be typical of its species and have a high similarity to other strains of that species. Type strains can be selected by taking the strain which has the highest average similarity to all the other strains, the centrotype, or by constructing a hypothetical mean organism (HMO; Tsukamura \& Mizuno, 1968) and taking the strain which has the highest similarity to it as the type strain. The typical Lspi strain cuB687 was selected by both methods, it had an average similarity to the other Lspi strains of $91 \%$ and was $96 \%$ similar to the HMO. We therefore propose that CuB687 become the type strain of the taxon Lspi. Selected distinguishing tests for Lspi are indicated by an asterisk in Table 3.

Cluster 2: Nocardia erythropolis/Jensenia canicruria. The similarity between Nocardia erythropolis (CUB646 and CUB642) and Jensenia canicruria (CUB647), reported by several workers, was again confirmed (Fig. 6). These three strains were also recovered, closely clustered together, by Goodfellow (197I) in his subgroup I4D, and Bradley (I97I) allocated CuB646 and CuB647 to his $N$. erythropolis group. Nocardia corallina (CuB673) of Batt \& Woods (I95I) also belongs to cluster 2. Three strains (cluster 7) join cluster 2 at a slightly lower similarity level: CUBI97, an isolate from Blelham Tarn mud, placed by Goodfellow (197I) on the edge of his subgroup I4D; CuB685, and a fungicide degrader isolated from soil by Bachofer et al. (1973); and CuB674, N. calcarea.

Cluster 3: Nocardia pellegrino. This clearly defined cluster is equivalent to cluster 14 subgroup A of Goodfellow (197I) and Goodfellow et al. (I972); it was also recovered by 
Tacquet et al. (197I). Strain CUB7II, provisionally named Nocardia corallina, belongs to this group.

Cluster 4: Gordona rubra. The strains сuB677 and cuB679 are both strains of G. rubra NCTCIC668 (ATCC25593).

Cluster 5: Gordona terrae. Strains CUB678 and CUB680 are duplicates of NCTCI0669 (ATCC25594). The $100 \%$ similarity between strain CUBI93 and its white mutant CUB686, and the high similarity between duplicates of G. rubra $(98 \%)$ and G. terrae $(96 \%)$ indicate that the majority of tests were reproducible. The tests in which the duplicates differed were utilization of sole carbon sources, e.g. raffinose.

Cluster 6: Gordona bronchialis. This cluster was more heterogeneous. Strains CUB68 I and CUB676, supposed to be duplicates of NCTC10667 (ATCC25592), were found to be only $83 \%$ similar. Strain CUB682 grew poorly on many media, and tended to die quickly on storage.

Other strains studied remained distinct and their affinities require further studies in a programme involving many more strains of the 'rhodochrous' complex.

\section{Identification of the Lspi cluster}

Taxonomic studies indicate that members of the 'rhodochrous' complex form a taxon quite distinct from the genera Mycobacterium, Nocardia and Corynebacterium (Bradley, 1971; Goodfellow, 1971; Tacquet et al., 1971; Goodfellow et al., 1972; Cross \& Goodfellow, 1973; Ridell \& Norlin, 1973; Tsukamura, 1973, 1974; Goodfellow et al., 1974; Jones, 1975; Alshamaony et al., 1976; Mordarski et al., 1976). The discovery of a common and hitherto unnamed nocardioform actinomycete, which undoubtedly falls within this complex, demands the choice of a suitable generic name before we can propose a new specific epithet. We have considered the possible names for this genus, namely Rhodococcus Zopf I891, Jensenia Bisset \& Moore 1950, Proactinomyces Jensen 1931 and Gordona Tsukamura $197 \mathrm{I}$.

Proactinomyces, advocated by Bradley \& Bond (1974), would have priority over Jensenia but its use would create considerable confusion. A recent classification of the actinomycetes (Krassilnikov, 1970) uses Proactinomyces to include aerobic and anaerobic nocardioforms and species currently classified in several alternative genera (Buchanan \& Gibbons, 1974). This dilemma can be overcome by observing rules of priority and choosing Rhodococcus. An authentic type species is available, Rhodococcus rhodochrous ATCCI 3808 (see Gordon, 1966), which was recovered in the 'rhodochrous' clusters I4C (Goodfellow, I971) and I $a$ (Goodfellow et al., 1974) during the course of extensive numerical studies. This opinion is supported by Tsukamura (1974).

The status of the genus Gordona (Tsukamura, I97I) remains a problem. We feel that the later suggestion (Tsukamura, 1973) that rhodochrous strains, including Rhodococcus rhodochrous, should be accommodated in Gordona was premature. The alternative should now be considered: can all the Gordona species be included within the genus Rhodococcus? Gordona species have been separated from rhodochrous strains in antibiotic sensitivity studies (Goodfellow \& Orchard, 1974), in lipid analyses (Alshamaony et al., 1976) and in DNA reassociation experiments (Mordarski et al., I976). However, in a numerical taxonomic study using Io9 characters, Tsukamura (1974) showed that strains of the 'rhodochrous' complex, including Rhodococcus rhodochrous ATCCI3808, and Gordona spp. formed a cluster at the $87 \%$ similarity level. He concluded that the appropriate generic name now appeared to be Rhodococcus and accordingly reclassified his Gordona spp. as species of Rhodococcus. Our results would not support the retention of a separate genus Gordona. 
The early descriptions of Gordona species (Tsukamura, Inagaki \& Kondo, 1970; Tsukamura, I97I) emphasized that the organisms were weakly or slightly acid-fast, particularly when grown on Lowenstein-Jensen or Ogawa egg media. Acid-fastness had been noted previously in species belonging to the 'rhodochrous' complex when grown in milk or on agar media containing glycerol (Gordon \& Mihm, 1957, 1959). The earlier studies of Erikson (I949) had emphasized the importance of the growth medium; strains then classified in the genus Proactinomyces produced acid-fast elements more often in media containing complex protein and fat and in chemically defined media containing paraffin or large quantities of glycerol.

There appear to be other recognizable species within the genus Rhodococcus. Our clusters including Nocardia erythropolis and $N$. pellegrino are obvious candidates together with $R$. rhodochrous, but the very limited studies reported here could not be used as a basis for such proposals. We do propose that cluster I, the Lspi cluster, should be considered a new species within the genus Rhodococcus and that it be named Rhodococcus coprophilus sp. nov. The specific name coprophilus (Gr.n. copros dung; Gr.adj. philus loving; M.L.adj. coprophilus dung loving) refers to the key role herbivore dung plays in the ecology of this organism (Rowbotham \& Cross, I977).

\section{Rhodococcus coprophilus sp. nov.}

Type strain CUB687, NCIBII 2 I I, NCTC10994, ATCC29080.

An aerobic, catalase positive, oxidase negative, mesophilic, thiamin-requiring nocardioform actinomycete. Rhodococcus coprophilus has a type IV wall composition, a DNA base composition of 60 to $64 \mathrm{~mol} \% \mathrm{GC}$, and contains lipid LCN-A type c. On Bennett's agar, after 2 weeks incubation at $30^{\circ} \mathrm{C}$, it forms small $2 \mathrm{~mm}$ diam. rhizoid colonies with a central orange papilla; growth into the agar also occurs. Pigmentation is enhanced by light. The young microcolonies on Bennett's agar are mycelial and after $24 \mathrm{~h}$ sparse, nonsporulating aerial hyphae are usually present. No macroscopic aerial mycelium, extracellular pigments or characteristic odours are produced. The central papilla of mature colonies is composed of complex aggregations of Gram-positive, non acid-fast, nonmotile coccoids (I to $\mathrm{I} \cdot 5 \mu \mathrm{m}$ diam.). Cystites may occur in the mycelial fringe of colonies on Bennett's agar. No pellicle is produced on the surface of Bennett's broth although isolated floating colonies may occur.

In contrast to many similar organisms, $R$. coprophilus does not utilize citrate, L-malate, succinate, butane-I,3-diol, glycerol, D-mannitol, sorbitol or any of the amino acids tested as the sole source of carbon and energy. It does not hydrolyse tyrosine and is more sensitive to polymyxin than related species.

Rhodococcus coprophilus grows on herbivore dung; it has been isolated from the dung of cows, sheep, goats, horses and donkeys. It is common on grass and in the soil beneath grazed pastures, and is washed into streams and lakes where it can accumulate in the sediment.

The authors are especially indebted to Dr M. Goodfellow and co-workers for reference strains, antibiotic discs and many useful discussions. The work was supported by the Natural Environment Research Council. 


\section{REFERENCES}

Alshamaony, L., Goodfellow, M., Minnikin, D. E. \& Mordarska, H. (I976). Free mycolic acids as criteria in the classification of Gordona and the 'rhodochrous' complex. Journal of General Microbiology 92, I $83-187$.

Bachofer, R., Oltmanns, O. \& Lingens, F. (1973). Isolation and characterization of a Nocardia-like soil bacterium, growing on carboxanilide fungicides. Archiv für Mikrobiologie 9o, I4I-I 49.

BATT, R. D. \& Woods, D. D. (I95I). The oxidation of thymine by an unidentified bacterium. Biochemical Journal 49, lxx-lxxi.

Becker, B., Lechevalier, M. P. \& Lechevalier, H. A. (1965). Chemical composition of cell wall preparations from strains of various form-genera of aerobic actinomycetes. Applied Microbiology 13, 236-243.

Bisset, K. A. \& Moore, F. W. (1950). Jensenia, a new genus of the Actinomycetales. Journal of General Microbiology 4, 280.

Bradley, S. G. (I97I). Criteria for definition of Mycobacterium, Nocardia and the 'rhodochrous' complex. Advancing Frontiers of Plant Sciences 28, 349-362.

BRADley, S. G. \& Bond, J.S. (I974). Taxonomic criteria for mycobacteria and nocardiae. Advances in Applied Microbiology 18, I $3 \mathrm{I}-190$.

Buchanan, R. E. \& Gibbons, N. E. (eds) (1974). Bergey's Manual of Determinative Bacteriology, 8th edn. Baltimore: Williams \& Wilkins.

Conn, H. J., Bartholomew, J. W. \& Jennison, M. W. (I957). Staining methods. In Manualof Microbiological Methods, pp. 10-36. Edited by M. J. Pelczar. New York: McGraw Hill.

Crawford, R. L., McCoy, E., Harkin, J. M., Kirk, T. K. \& ObST, J. R. (I973). Degradation of methoxylated benzoic acids by a Nocardia from a lignin-rich environment: significance to lignin degradation and effect of chloro substituents. Applied Microbiology 26, 176-1 84.

Cross, T. \& AtTWELl, R. W. (I974). Recovery of viable thermoactinomycete endospores from deep mud cores. In Spore Research 1973, pp. I I-20. Edited by A. N. Barker, G. W. Gould and J. Wolf. London and New York: Academic Press.

Cross, T. \& Collins, V. G. (I966). Micromonospora in an inland lake. In IX International Congress for Microbiology, Moscow, abstracts of papers $\mathrm{C}_{5}$, p. 339. (I I pp., cyclostyled: Collected Papers of the Freshwater Biological Association No. 639).

Cross, T. \& Goodfellow, M. (1973). Taxonomy and classification of the actinomycetes. In Actinomycetales: Characteristics and Practical Importance, pp. I I-I I 2. Edited by G. Sykes and F. A. Skinner. London and New York: Academic Press.

Cure, G. L. \& KedDie, R. M. (I973). Methods for the morphological examination of aerobic coryneform bacteria. In Sampling: Microbiological Monitoring of Environments, pp. 123-I 35. Edited by R. G. Board and D. W. Lovelock. London and New York: Academic Press.

Eggins, H. O. W. \& Pugh, G. J. F. (1962). Isolation of cellulose decomposing fungi from the soil. Nature, London 193, 94-95.

ERIKSON, D. (1949). Differentiation of the vegetative and sporogenous phases of the actinomycetes. 4. The partially acid-fast proactinomycetes. Journal of General Microbiology 3, 36I-368.

Goodfellow, M. (I97I). Numerical taxonomy of some nocardioform bacteria. Journal of General Microbiology 69, 33-80.

Goodfellow, M. \& Orchard, V. A. (1974). Antibiotic sensitivity of some nocardioform bacteria and its value as a criterion for taxonomy. Journal of General Microbiology 83, 375-387.

Goodfellow, M., Fleming, A. \& SaCkin, M. J. (1972). Numerical classification of 'Mycobacterium' rhodochrous and Runyon's group IV mycobacteria. International Journal of Systematic Bacteriology 22, 8I-98.

Goodfellow, M., Lind, A., Mordarska, H., Pattyn, S. \& Tsukamura, M. (1974). A co-operative numerical analysis of cultures considered to belong to the 'rhodochrous' taxon. Journal of General Microbiology 85, 29I-302.

Gordon, R. E. (I966). Some strains in search of a genus - Corynebacterium, Mycobacterium, Nocardia or what? Journal of General Microbiology 43, 329-343.

Gordon, R. E. (1968). The taxonomy of soil bacteria. In The Ecology of Soil Bacteria, pp. 293-321. Edited by T. R. G. Gray and D. Parkinson. Liverpool: Liverpool University Press.

Gordon, R. E. \& MinM, J. M. (1957). A comparative study of some strains received as nocardiae. Journal of Bacteriology 73, I5-27.

Gordon, R. E. \& MiHM, J. M. (I959). A comparison of four species of mycobacteria. Journal of General Microbiology 21, 736-748.

Jefrries, C. D., Holtman, D. F. \& Guse, D. G. ( 1957 ). Rapid method for determining the activity of microorganisms on nucleic acids. Journal of Bacteriology 73, 590-59I.

JENSEN, H. L. (I93I). Contributions to our knowledge of the Actinomycetales. II. The definition and subdivision of the genus Actinomyces, with a preliminary account of Australian soil actinomycetes. Proceedings of the Linnaean Society of New South Wales 56, 345-370. 
Johnston, D. W. \& CROss, T. (1976). The occurrence and distribution of actinomycetes in lakes of the English Lake District. Freshwater Biology 6, 457-463.

JoNEs, D. (1975). A numerical taxonomic study of coryneform and related bacteria. Journal of General Microbiology 87, 52-96.

Krassilnikov, N. A. (1970). Actinomycetes. Moscow: Academy of Science of the USSR, Institute of Microbiology (in Russian).

KüTZNER, H. J. (1972). Storage of Streptomyces in soft agar and by other methods. Experientia 28, 1395I396.

LECHEVALIER, M. P. (I968). Identification of aerobic actinomycetes of clinical importance. Journal of Laboratory and Clinical Medicine 7r, 934-944.

Lessel, E. F. \& Holt, J. G. (I970). Presenting and interpreting the results. In Methods for Numerical Taxono$m y$, pp. 50-58. Edited by W. R. Lockhart and J. Liston. Bethesda, Maryland: American Society for Microbiology.

McClung, N. M. (1954). Morphological studies in the genus Nocardia. III. The morphology of young colo nies. Annals of the New York Academy of Sciences 60, 168-18I.

MCClung, N. M. (1960). Isolation of Nocardia asteroides from soils. Mycologia 52, I54-156.

Minnikin, D. E. \& Goodfellow, M. (1976). Lipid composition in the classification and identification of nocardiae and related taxa. In The Biology of the Nocardiae, pp. I60-219. Edited by M. Goodfellow G. H. Brownell and J. A. Serrano. London and New York: Academic Press.

Mordarska, H., Mordarski, M. \& Groodfellow, M. (1972). Chemotaxonomic characters and classification of some nocardioform bacteria. Journal of General Microbiology 71, 77-86.

Mordarski, M., Szyba, K., Pulverer, G. \& Goodfellow, M. (1976). Deoxyribonucleic acid reassociation in the classification of the 'rhodochrous' complex and allied taxa. Journal of General Microbiology 94 , 235-245.

Mordarski, M., Goodfellow, M., Szyba, K., Pulverer, G. \& Tkacz, A. (1977). Classification of the 'rhodochrous' complex and allied taxa based upon deoxyribonucleic acid reassociation. International Journal of Systematic Bacteriology 27, $3 \mathrm{I}-38$.

Perkins, H. R. (1965). 2,6-Diamino-3-hydroxypimelic acid in microbial cell wall mucopeptide. Nature, London 208, 872-873.

Ridell, M. \& Norlin, M. (1973). Serological study of Nocardia by using mycobacterial precipitation reference systems. Journal of Bacteriology $\mathbf{1 1 3}, \mathrm{I}-7$.

Robertson, J. G. \& BATt, R. D. (1973). Survival of Nocardia corallina and degradation of constituents during starvation. Journal of General Microbiology 78, I09-I I 7 .

Rowbotham, T. J. \& Cross, T. (1977). Ecology of Rhodococcus coprophilus and associated actinomycetes in freshwater and agricultural habitats. Journal of General Microbiology (in the Press).

SIERRA, G. (1957). A simple method for the detection of lipolytic activity of micro-organisms and some observations on the influence of the contact between cells and fatty substrates. Antonie van Leeuwenhoek 23, $15-22$.

Soxal, R. R. \& Michener, C. D. (1958). A statistical method for evaluating systematic relationships. Kansa, University Science Bulletin 38, 1409-1438.

STEEL, K. J. (I96I). The oxidase reaction as a taxonomic tool. Journal of General Microbiology 25, $297-306$.

StEVEnson, I. L. (1967). Utilisation of aromatic hydrocarbons by Arthrobacter spp. Canadian Journal of Microbiology 13, 205-2II.

Tacquet, A., Plancot, M. T., Debruyne, J., Devulder, B., Joseph, M. \& Losfeld, J. (1971). Études préliminaires sur la classification numérique des mycobactéries et des nocardias. I. Relations taxonomiques entre Mycobacterium rhodochrous, Mycobacterium pellegrino et les genres Mycobacterium et Nocardia. Annales de l'Institut Pasteur de Lille 22, 121-1 35.

Tsuramura, M. (197I). Proposal of a new genus, Gordona, for slightly acid-fast organisms occurring in sputa of patients with pulmonary disease and in soil. Journal of General Microbiology 68, I 5-26.

Tsukamura, M. (1973). A taxonomic study of strains received as 'Mycobacterium' rhodochrous. Description of Gordona rhodochroa (Zopf; Overbeck; Gordon et Mihm) Tsukamura comb. nov. Japanese Journal of Microbiology 17, 189-197.

Tsukamura, M. (I974). A further numerical taxonomic study of the rhodochrous group. Japanese Journal of Microbiology 18, 37-44.

Tsukamura, M. \& Mizuno, S. (I968). 'Hypothetical mean organisms' of mycobacteria. A study of classification of mycobacteria. Japanese Journal of Microbiology 12, 37 I-384.

Tsukamura, M., Inagaki, H. \& Kondo, H. (1970). A case report on a patient with pulmonary disease excreting frequently 'Mycobacterium' rhodochrous-like organisms. Kekkaku 45, I 53-I 57.

WilloughBy, L. G. (1969). A study of the aquatic actinomycetes of Blelham Tarn. Hydrobiologia 34, 465483.

ZopF, W. (I89r). Ueber Ausscheidung von Fettfarbstoffen (Lipochromen) seitens gewisser Spaltpilzes Berichte der Deutschen botanischen Gesellschaft 9, 22-28. 